\title{
RESEARCH ON THE PUBLIC SPACE RENEWAL STRATEGY OF CHINESE TUJIA NATIONALITY HERITAGE VILLAGES BASED ON THE HEALTHY RURAL THEORY: A CASE STUDY OF LIANGHEKOU VILLAGE IN ENSHI XUANEN COUNTY, HUBEI PROVINCE
}

\author{
CHEN LI \\ Chongqing University 400044, PR China
}

\begin{abstract}
In recent years, certain transformations have taken place in the existing mode of Chinese towns and villages in the wake of tourism flourishing that increasing numbers of towns and villages have begun to redefine themselves as rural tourism-oriented. Such transformations have witnessed positive economic growth for China while affecting the original life of the rural residents. As a result, myriads of time-honored villages and towns are confronted with virtual threats and challenges triggered by heritage loss and cultural interruption. In 2008, Lianghekou Village of Enshi Tujia and Miao Autonomous Prefecture, Hubei Province, was listed in the fourth batch of cultural and historical villages. Since the expressway was conveniently accessible in 2019 , considerable quantities of visitors have swarmed into this village initially unheeded. Accordingly, the Tujia folklore characterized by Pengiiazhai, a nationally-protected cultural relic of Tujia Ethnic Group, has become a treasured cultural heritage with extra attention garnered and popularity gained. Taking Lianghekou Village, Shadaogou Town of Enshi, Hubei Province for example, this essay launches a probe into how the public space of Chinese historical villages should be maintained, sustained and renewed with the healthy and active village space theory introduced. Focusing on protecting and succeeding the traditional culture of Tujia Ethnic Group, it further makes a planning for the public space of Lianghekou traditional village based on analyses of the village texture and space function, node space, street space, as well as public architectural forms. Meanwhile, a tactic incorporating using active and healthy space, creating healthy rural production mode, integrating plural space, and improving village public facilities is proposed so as to provide a mirror for the renewing and renovation of the public space of the historical and cultural village, rejuvenate the village amid times development, and get the cultural heritage commonly owned by mankind well protected.
\end{abstract}

Keywords: traditional village, landscape optimization, public space, heritage protection.

\section{INTRODUCTION}

Improving the living environment in rural areas is a key task for the development and promotion of Chinese villages and towns. The improvement of rural living environment plays a positive role in promoting the development of rural revitalization, the happiness value of villagers' life and the inheritance of village culture [1]. While, due to the development of tourism in recent years, the development mode of China's rural areas has changed to a certain extent, and more and more villages and towns have begun to transform into rural tourism towns. Such a transformation not only brings positive economic development to China, but also often affects the lives of residents in original towns [2]. A large number of century-old towns are faced with realistic threats and challenges such as heritage loss and cultural dating. On the other hand, the protection and inheritance of Chinese villages are still more at the level of slogans and instructions, which is actually not conducive to the sustainable development of villages. The development of expressways has changed the economic and social situation of China and exerted a profound influence on the way of life of Chinese 
people. The huge population mobility and urbanization also reflect the face of Chinese society in many aspects.

From 2003 to January 2019, The Ministry of Housing and Urban-Rural Development and the State Administration of Cultural Heritage began to jointly publish seven batches of Chinese historical and cultural famous towns and villages, and the number of national-level historical and cultural famous towns in China reached 799, covering 31 provinces, autonomous regions and municipalities [3]. China attaches great importance to famous towns, which indicates the importance of protecting them. These famous towns and villages reflect the settlement forms and evolution process formed by different regions, nationalities, economic and political development stages in China, and truly record the traditional architectural features, excellent historical context, simple folk customs and primitive spatial settlements. It contains the traditional features of historical and cultural villages and towns in different regions, which is of great research value and protection significance.

In recent years, the academic circle has conducted extensive research and discussion on "rural heritage". As a common treasure of human civilization, the inheritance and protection of rural heritage has been paid increasing attention to. The main focus is on settlement development history, spatial settlement layout, renewal and utilization of village public space, cultural customs and economic policies, etc. [4]. Paul related to natural rural heritage and local economic system, such as correlation analysis, focuses on the economic development of a variety of influence on the rural heritage, on rural environment condition, range, source, measures and linkage analysis, to explore the external environment and the economy of country natural heritage represented by different types in different regions of Scotland [5]. Jin Cao believes that the protection of rural heritage should start from caring for the wishes of the main villagers, reconstruct the rural spirit with minimal intervention in a patching and gradual manner, and stimulate the vitality of the countryside through a micro perspective to protect and utilize the original village context in a small way [6]. Jie Zhang in according to current situation of rural tourism industry hot, in the face of cultural heritage protection "solid old" and "reform" of the problem, explore the root of influencing factors, based on the regional perspective model system of rural development, and between local economic and cultural resources, the nature of the return to heritage protection planning, find out the adapted to different rural development source protection so as to suit the remedy to the case according to the particularity of rural [7].

The public space of traditional villages is the main material place for villagers to live and carry out activities, and also an important part of the village environment. To a certain extent, the public space of a village reflects the shape of the village, the basic living conditions of villagers, the cultural customs that continue to this day, and the internal stable social order. However, with the intensification of urbanization and the weak protection awareness of villages, most of the public Spaces in many traditional villages with rich history and culture have been abandoned. On the other hand, the transformation of rural economic model with the development of The Times is an inevitable trend, and the traditional inherent public space can no longer meet the existing living requirements of villagers. Therefore, under the background of public communication based on the existing social relations, it is of great practical significance to protect and explore the new mode of rural public space. This many previous studies, there is a certain concept of the cognition of Chinese towns. This research focus on what kind of scenario model will appear in towns in the context of rapid economic development. The needs of villagers follow the economic what kind of change will occur due to use the methods of field research, interviews and model analysis to find the problems in the public space of Chinese towns. Analyze the current situation and explore the strategies that can be solved. 


\section{CHARACTERISTICS OF PUBLIC SPACE IN LIANGHEKOU VILLAGE}

\subsection{Summary of Lianghekou Village}

Enshi Tujia and Miao Autonomous Prefecture in Hubei province, referred to as Enshi Prefecture. Hubei province is the only minority autonomous prefecture, located in the southwest of Hubei Province, located in Hubei, Hunan, Chongqing three provinces junction. Tujia is the main ethnic component of Enshi Prefecture, as shown in Fig. 1, which witnessed the development and inheritance of Tujia culture, and also accompanied by the development and changes of Tujia people from generation to generation. With its unique geographical location and environmental resources, Tujia people have developed many unique customs and political systems since ancient times. In recent years, some cultural life customs have become intangible cultural heritage. Lianghekou Village, Xuanen County, Enshi Prefecture, was rated as one of the fourth batch of historic and cultural villages by the Ministry of Housing and Urban-rural Development in 2008. As shown in Fig. 2, it has important protection value because it has a long history and still retains rich cultural connotation and a large amount of material heritage in the development process of hundreds of years. In the Ming and Qing Dynasties, Lianghekou Village was a commercial village along the "Sichuan Salt Aid Chu" salt road, which is still well preserved. In recent years, with the establishment of famous historical and cultural villages, the number of foreign tourists in Lianghekou Village has increased. The present situation of public space in towns are discussed and corresponding countermeasures are put forward. On the basis of strict protection, appropriate renewal and transformation should be carried out according to certain requirements to ensure the inheritance and protection of villages and the sustainable development of resources.
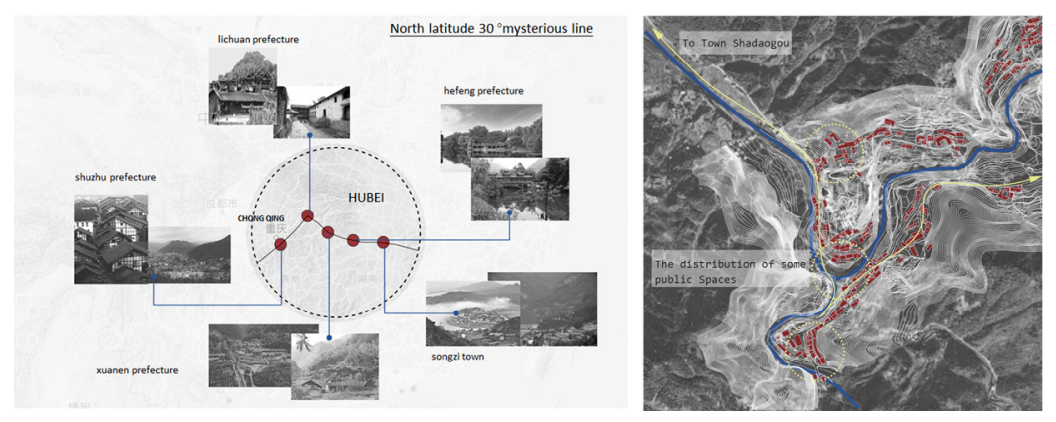

Figure 1: The relationship between the geographical location and texture of the village.

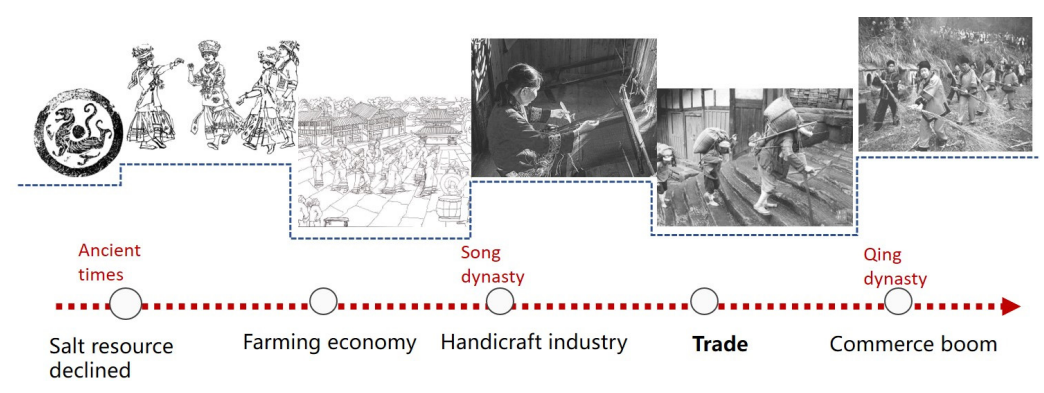

Figure 2: Tujia development process. 


\subsection{Basic features of the existing public space in Lianghekou Village}

Through a variety of ways to information collection, such as literature reading, data collection, field investigation, questionnaire and interview with the villagers in the village, the public space can be truly presented, can reflect the actual situation of the village and the villagers from the side of the actual will. And through comprehensive investigation and analysis can sum up the existing Lianghekou Village public space of several major issues (Fig. 3).
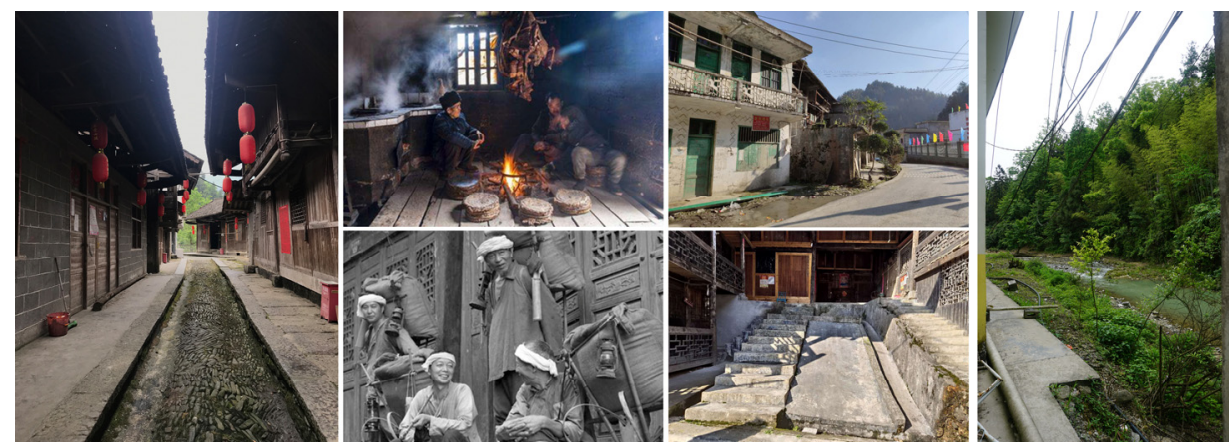

Figure 3: Current situation of Lianghekou Village.

\subsubsection{With the rapid development of urbanization, spatial feelings are weakened}

The construction and improvement of public space can promote the daily communication among residents and enhance the neighborhood relationship among residents. However, with the rapid development of urbanization, rural areas in China are gradually influenced by cities. The villagers who grew up here began to feel less self-identified with the village they lived in and began to yearn for a prosperous urban life. Villages and towns have not formed a good cycle of development mode, but blindly pursue the development of "urbanization". This situation is likely to cause the destruction of the original emotions in villages and towns. The public space of Lianghekou Village is also facing the same threat. Spatial relationships preserved in traditional societies are no longer fully applicable to the use of existing rural residents, and formerly bustling villages are beginning to be abandoned. In terms of function and life form, the existing rural residents also have higher requirements for public space, and diversified functional Settings should be considered, as well as more diversified reconfigurable space.

\subsubsection{With the population loss intensifying, the rural context is missing}

Culture provides spiritual support and cultural nourishment for rural revitalization and development. Lianghekou Village, relying on Enshi Tujia culture, has a rich and precious heritage since ancient times. For example, the famous Tujia handicraft culture, traditional Tujia folk dance, folk paper-cut and so on. Due to the rapid loss of rural population in recent years, a large number of children and old people remain in towns. And the loss of young and middle-aged population leads to the serious crisis of the loss of traditional culture.

\subsubsection{With weak infrastructure, functional requirements are rising}

Based on the on-the-spot investigation of the village, it is concluded that the village is lack of public space dedicated for villagers' daily activities and communication. The lack of 
basic activity facilities cannot meet the basic living needs of villagers, leading to the fact that villagers, especially the elderly and children do not have exclusive activity facilities. In terms of life service facilities, due to the small gap between the houses on both sides of the old street, some of them are built in front of the street, which leads to the lack of attention paid to the fire protection facilities and system in the village. It is obvious that problems of garbage recycling and road lighting at night. In order to avoid affecting the overall landscape environment of the village, service facilities should be improved.

2.2.4 The ecological environment is effected and the landscape form is single

A mix traditional village is not only a single building, but also the environment construction and human unified combination of complex. Environment means that a concreteness and particularity, is the exclusive feature of space, is the basic environment, generations of villagers to build on this land and life, Lianghekou Village's landscape pattern is since one hundred by natural environment, culture, economic and political common results. Therefore, villages have unified features on the whole, which reflect the basic morphological attributes of settlements on the most macroscopic level. Villages often lack unified planning in the early stage, which leads to the widespread phenomenon of spontaneous construction by villagers. Due to the weak protection consciousness of villagers and the destruction of foreign tourists, the ecological environment is affected to a certain extent. Some of the facilities are dilapidated due to the old age, which has an impact on the rural landscape, and the decline of visual effect leads to the decline of environmental quality.

\section{ANALYSIS OF THE PUBLIC SPACE MORPHOLOGY OF LIANGHEKO VILLAGE}

\subsection{Street and lane spatial form}

Street and lane space is an important part of rural public space, which is not only a key element to connect villages inside and outside, but also an important part to organize rural transportation. Street space is often composed of nodes, plane form, road size, street-facing building and other elements. The street can be used as an ordinary traffic space, or as a place for the villagers to communicate and rest, bearing the villagers' basic daily activities and economic activities. Under the eaves of the buildings on both sides of the street, a transition space between the street and the building can be formed economic activities. Under the eaves of the buildings on both sides of the street, a transition space between the street and the building can be formed. The starting point and ending point of the road are also particularly critical in this space system, which is helpful to locate the node transition space of the street and lane. In Lianghekou Village, the main and secondary roads are relatively clear, usually with a main street running through and extending like a tree. However, the starting and ending positions of the roads lack a clear transition space. The layout of the street system is relatively free, with obvious traces of natural growth, and often has a strong overall and coherent (Fig. 4). Therefore, in the reconstruction of the streets and lanes in Lianghekou Village, the pleasant small-scale scale should be maintained. In combination with the living habits and traffic needs of the residents in the village, the width can be appropriately increased to set aside places for communication and interaction. The gap between the buildings on both sides of the street and the original height should not be too large. Proper adjustment can enrich the vertical landscape. The width of the street needs to be limited to make it feel close and warm. 

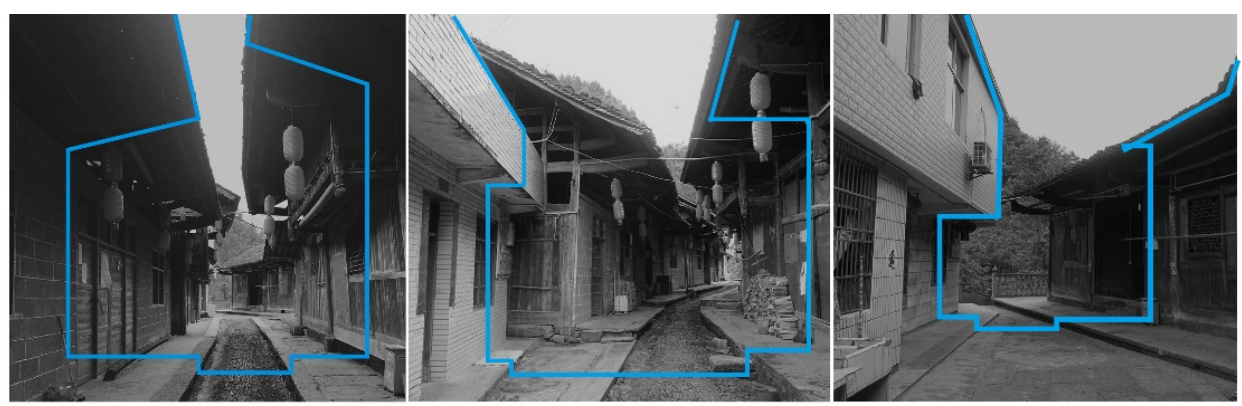

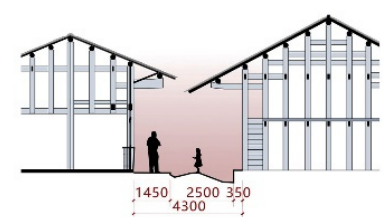

MEDIUM

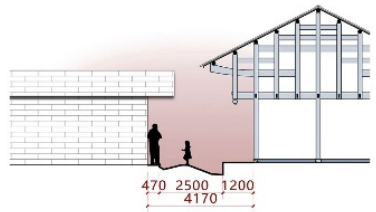

NARROW

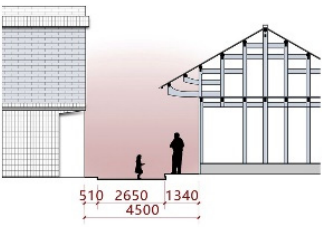

CAPACIOUS

Figure 4: Street scale of Lianghekou Village.

\subsection{Node spatial morphology}

In addition to activities in their houses, residents in villages will also spontaneously form some social activities outside, with varying degrees of scope. Therefore, some node spaces will naturally form in villages, such as squares, the end of streets, markets and so on. These node Spaces tend to be generated by crowd gathering frequency and adaptation to the terrain and other factors. They are more attractive that based on the actual living needs of the people, and the appropriate scale and environment. The end of the old street in the village often lacks a regional square where villagers can gather and gather. There are many left-behind children and old people in the village, so it is necessary to create suitable places for them to have activities (Fig. 5).
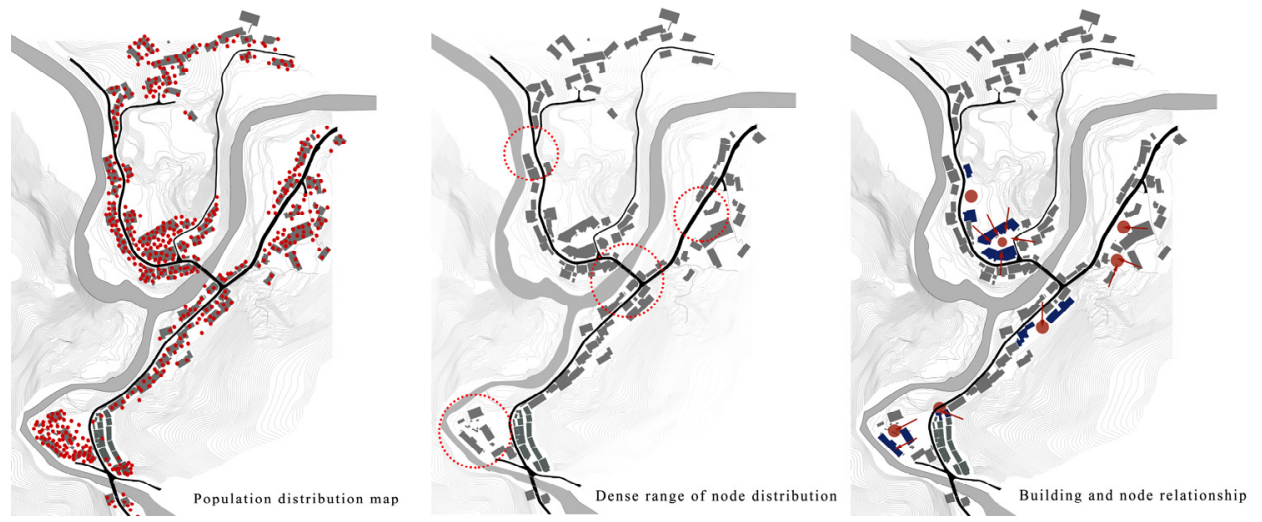

Figure 5: The source and spatial distribution of some important nodes. 


\subsection{The spatial form of public buildings}

The characteristic public building is also a kind of building method to the space. It is the space that contains spirit attribute above all, Tujia fire pond space is the space that contains spirit attribute, every family installs fire pond, cook food to meet conveniently, often installed in the living room and kitchen. Secondly, Stilted buildings are the traditional dwelling houses of Tujia family. And they are a unique architectural form of Tujia family. Wooden pillars are used to support two or more floors on flat or mountainous areas. The lower layer is a pen for pigs and cattle or used to pile up debris. The second floor of a stilted building is usually surrounded by a curving gallery, which is usually equipped with railings. On the one hand, these public buildings express the Tujia spirit and promote the development of tourism to attract tourists to visit the story behind their buildings. On the other hand, local villagers continue the familiar emotions left by traditional history through public buildings.

\section{SOLUTIONS TO EXISTING PUBLIC SPACE IN LIANGHEKOU VILLAGE}

\subsection{Use the positive health space}

A positive and healthy public space can not only attract tourists to learn about Tujia culture, but also serve as a spiritual fortress in the heart of Tujia villagers. A good place can generate emotional resonance. To create a positive and healthy space includes, first, to clear the unused land in the village. To continue the overall spatial style of Lianghekou Village, illegal buildings can be demolished, and facades affecting the overall style can be renovated to ensure the integrity and unity of the street space. Second, due to the development of villagers' lifestyle, the functional properties of some original buildings with public attributes gradually weaken, such as the old temples and ancestral shrines, and some old residential buildings with large space have been abandoned due to the long time of being uninhabited. These sites cause a waste of space resources. According to the field survey, there are not a few houses in the village that have not been used for a long time, and many Spaces that are still in use are not well used [8]. Therefore, while protecting the original public buildings, it is necessary to inject new functions and improve the use of public space. For example, the original ancestral temple or historical residence can be transformed into a modern public space such as a village activity center, a stage, and an exhibition area of folk culture. The original Lianghekou Old Street was an important hinge of the Salt Road in the Ming and Qing Dynasties, but it has lost its original function now. However, the steps at the entrance of the Old Street can be transformed into an outdoor terrace and rest area according to the basic needs of villagers. The reuse of negative public space makes villages rejuvenated and possible.

\subsection{Combine the characteristics of rural culture}

No matter how the countryside develops, its unique culture and context are its enduring foundation. The profound Tujia civilization has laid down the cultural resources of Lianghekou Village. These resources are closely related to the basic necessities of local villagers. Today, with the rapid development of tourism, it is even more important to integrate and preserve the homesickness and distinct regional culture of Tujia, and provide a resource base for the renewal of rural public space. Firstly, we explore Tujia culture and its unique folk customs, and makes a systematic analysis of the form classification, existing situation and value resources of Tujia culture through on-site visits, book reading, literature review and other methods. In view of the culture that is about to be lost, timely remedial measures should be taken to sort out the rational use of cultural resources. Secondly, for rural resources. 
In the process of integration, focus on the exploration of the real economy of cultural and industrial value (Fig. 6), and explore some of the original real economy and the current form of innovative models, which can create public space activities that foreign tourists and local villagers can participate in.

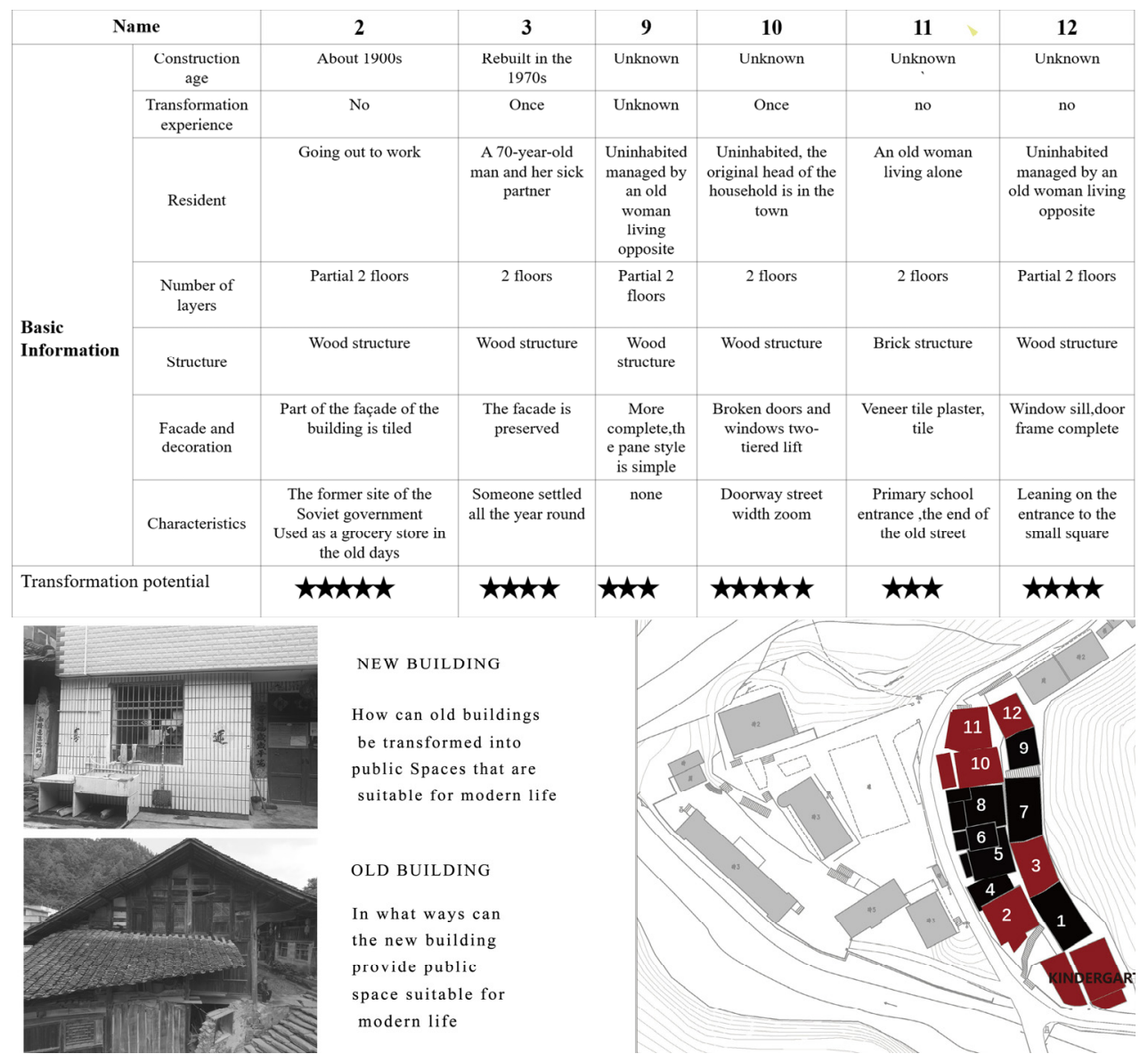

Figure 6: Introduction of some specific houses in the village.

In the Tujia area, the production of cured meat has a long history, so we can organize the production process in the area near the square or the window facing the street. In the process of participation, not only the villagers' cultural identity and confidence to the local culture, but also the attraction of the rural public space has been enhanced invisibly.

\subsection{Complex multi-space integration}

Space construction under a single mode will cause many deficiencies, nowadays, the transformation and renewal of rural public spaces should be integrated with the times on the basis of preserving the original traditional culture, expanding innovation. Inheriting the unique culture and folk customs, such as Tujia hand-waving dance, a certain area of 
distribution square should be set up in the construction of space. It can be used as a functional place during special festivals, and it can also provide a place for villagers to rest and improve communication between neighbors. Public space is not only a transmission of function and form, but also an expression of order. In the construction of public space, the wishes of local villagers should be respected and should not be constructed overhead. When renewing the space, meeting people's functional needs and incorporating a sense of identity that can carry the memories and feelings of the countryside will also help to a certain extent in reshaping the concept of rural values. On the other hand, with the increase of foreign tourists, some traditional public spaces can no longer be used, and the demand for village public spaces has increased (Fig. 7). As a result, some traditional spaces have been idle or declined. Under the opportunity of the new era, how to make the public space activities of villagers richer and more diverse is also very important. In terms of the boundaries of the boundary, the sense of boundary of the new rural public space will gradually expand, and it will often be connected with the architecture [9].
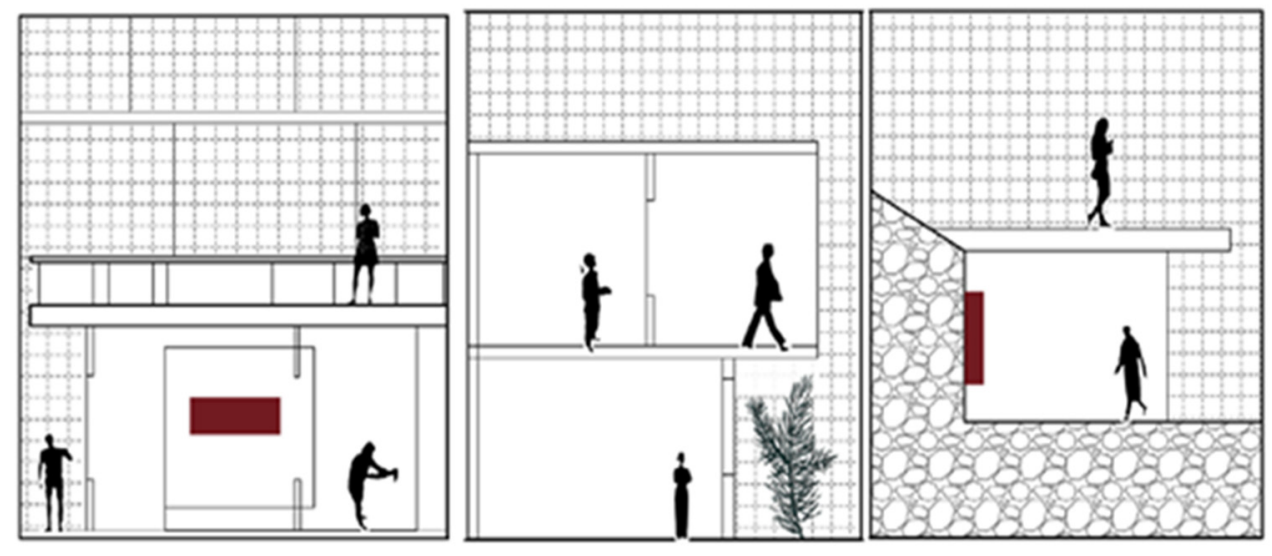

Figure 7: Some design plans for public spaces.

For example, a representative old building at the beginning of the Old Street in Lianghekou Village, as the beginning end of the entire old street, the overall design of the boundary helps to better substitute people into this street. This is a historic building that is more than 100 years old, the interior of the building is extremely rich due to the terrain and the villagers' own construction. From the perspective of external space, the architectural form is more rich and creative. It is precisely because of the special geographical location and the complexity of the space that the design hopes to allow the static buildings to be performed through scene superimposition, and to better interact with the venue, the old street and the passing people. Using modern scientific means to protect it, while giving new functions. By reorganizing the height difference, using small staggered floors and stairs to create more interesting spaces, which is also an optimization of the living space. Keep the location of the firepit and set up a small shop that can sell ham to the outside. The second floor is set up as a tea house and exhibition rest space, interacting with the surrounding scenery and large steps. The third floor of the old street is close to the kindergarten and hopes to leave more space for the children. It is set as a folklore experience hall for parents to bring their children to experience (Fig. 8). 


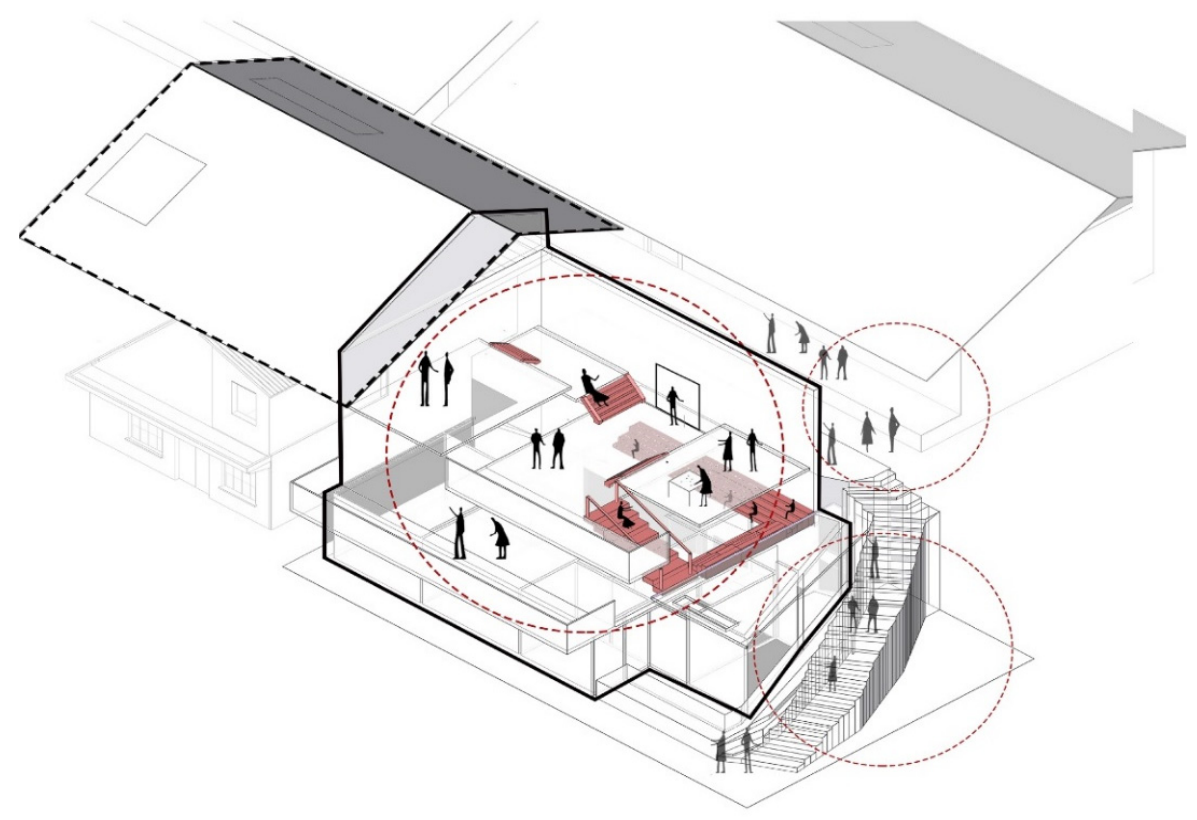

Figure 8: The relationship between public space and residents.

\subsection{Improve rural public facilities}

In view of the dilapidated and imperfect public facilities mentioned above, it can be solved from two aspects. Firstly, the old facilities should be replaced. There are more left-behind children and elderly in Lianghekou Village. When public facilities are replaced, different groups of people should be reasonably distributed. Lianghekou Elementary School is close to the old street. There are not many spaces for children to play in the elementary school. If the public space of the old street is renewed, it is possible to consider implanting activities for school-age children. The elderly in Lianghekou usually stay in their homes, there are not many places to participate in activities, and there is also a lack of communication and exchanges between neighbors. The scene that can be seen is that there are usually elderly people resting under the eaves in front of their houses. Therefore, it is necessary to improve the mentality and activities of the elderly, and at the same time, carry out targeted investigation and understanding of the majority of the population and the current situation in the village. Finally, in the old street, it is necessary to strengthen the improvement of service facilities to meet the needs of the villagers' leisure life. The existing canteen at the village head is far away from the old street and the materials are scarce. In the renovation and reconstruction of the public space, it is recommended to develop the village appropriately. Public service centers and facilities.

\section{CONCLUSION}

Through the research on the problems existing in the public space in Chinese historical and cultural villages, based on the concept of healthy villages, some planning strategies that can be used for reference in general villages are proposed. After Lianghekou Village was rated as a famous historical and cultural village, Tujia culture has gradually become 
known to everyone, and it has brought about the development of tourism. However, there are many problems in the lives of local residents, and the historical heritage is at risk of being abandoned. Through the investigation and research on the development status of Lianghekou Village and the villagers' willingness to develop, it has triggered some reflections on the renewal of the rural public space, and considering the serious aging problem of the village's current status, the planning and construction of the community will help. To a certain extent, solve the problems of unattended elderly and unattended children in rural areas, transform the contradictions of the current rural situation into development motivation, and get some thinking on the above-mentioned planning landscape strategy level.

\section{ACKNOWLEDGEMENTS}

The authors would like to acknowledge Prof. Dongzhu Chu for his guidance on this research. We also appreciate master Candidate Jin Jing Huang for her valuable suggestions on this article.

\section{REFERENCES}

[1] Benson, P.L. et al., Beyond the "Village" Rhetoric: Creating healthy communities for children and adolescents. Applied Developmental Science, 16(1), pp. 3-23, 2012.

[2] Kaiumars, K., Healthy cities and healthy villages, how to tackle health and environmental problems in urban and rural areas. Eastern Mediterranean Health Journal, 1(1), pp. 103-111, 1995.

[3] Xiao, J. \& Yue, J., The protection and rejuvenation of China's rural cultural heritage during the model transition period: A case study of Yunfeng Tunpu in Guizhou. Urban Planning Journal, 4, pp. 70-78, 2019.

[4] Zhang, L. \& Liu, L., The strategy of rural public space construction under the background of rural revitalization: A case study of Beibei Berlin Village in Chongqing. Journal of Anhui Agricultural Sciences, 48(10), pp. 46-49, 2020.

[5] Courtney, P., Hill, G. \& Roberts, D., The role of natural heritage in rural development: An analysis of economic linkages in Scotland. Journal of Rural Studies, 22(4), 2006.

[6] Cao, J., Caring and awakening-Inheritance and renaissance of rural cultural heritage from a micro perspective. Architectural Journal, 1, pp. 118-120, 2017.

[7] Zhang, J., The "consolidation" and "renovation" of the protection of rural cultural heritage under rural revitalization-Also on the interpretation of the rural development system in the past 40 years of reform and opening up. Planners, 34(10), pp. 26-31, 2018.

[8] Guy, H., A Guide for Communities and Community Health Workers, World Health Organization: Geneva, 2002.

[9] Thi Trinh, T., Ryan, C. \& Duc Bui, H., Heritage, education and processes of change in Vietnamese rural tourism: A case study from Hoi An. Journal of Vacation Marketing, 26(3), pp. 378-394, 2020. 